\title{
Physical and Morphological Effects of Cellulose Nano- fibers and Nano-clay on Biodegradable WPC Made of Recycled Starch and Industrial Sawdust
}

\author{
Salomeh Esmaeilzadeh Saieh, ${ }^{\mathrm{a}}$ Habibollah Khademi Eslam, ${ }^{\mathrm{a}, *}$ Esmaeil Ghasemi, \\ Behzad Bazyar, and Mohammad Rajabi ${ }^{\mathrm{c}}$ \\ Effects of adding small amounts of cellulose nanofibers and nanoclay \\ particles on physical and morphological properties of biodegradable \\ composites made of starch thermoplastic polymer and industrial sawdust \\ were investigated. For this purpose, these nanoparticles were mixed with \\ wood plastic composites (WPCs) at $0 \%, 3 \%$, and $5 \%$ weight percent. \\ Water absorption, thickness swelling, thermal dynamic mechanical tests, \\ and also degradation tests were performed according to corresponding \\ standard test methods. The results showed that adding small amounts of \\ cellulose nanofibers and nanoclay particles can be successfully used as \\ filler and improve overall performance of the above-mentioned WPCs.
}

Keywords: Biodegradable nanocomposite; Cellulose nanofiber; Nanoclay; Industrial sawdust; Thermoplastic starch polymer

Contact information: a: Department of Wood and Paper Science and Technology, Faculty of Natural Resources and Environment, Science and Research Branch, Islamic Azad University, Tehran, Iran; b: Iran Polymer and Petrochemical Institute, P. O. Box:14965/115, Tehran, Iran; c: Department of Mechanical Engineering, Faculty of Engineering, University of Tehran, Tehran, Iran;

* Corresponding author: hkhademieslam@gmail.com

\section{INTRODUCTION}

The environmental preservation of forests and the reduction of fossil fuel usage has become increasingly important. Some of the materials that have been considered in this way are composites (Keller 2003; Eslam et al. 2011). Consequently, the use of different and more environmentally friendly materials in the fabrication of composites has become more widespread. Composites made of thermoplastic polymers as matrix and synthetic fibers (glass, mica, carbon, etc.) or natural fibers (wood fibers and lignocellulose) as filler have shown more popularity and growth due to their desirable properties (Eslam and Samariha 2015). Because synthetic polymers are non-degradable and remain in the environment for a very long time, biodegradable polymers such as starch have been considered (Jiménez et al. 2012). As filler materials, natural fibers have advantages such as low cost, low density, good mechanical properties, and most importantly, their renewable and degradable characteristics (Teixeira et al. 2012).

Because thermoplastic starch has poor mechanical properties and is very hydrophilic (Dufresne and Vignon 1998; Cunha and Gandini 2010), it cannot provide the proper features for many applications such as packaging. To overcome this problem starch can be combined with some other fillers and modifying materials. Nanoparticles improve WPC properties better than other fillers due to their special dimensions and exceptional properties (Beigloo et al. 2017).

Nanoclays are minerals that have attracted much attention in the field of WPCs; the 
addition of small amounts of nanoclay particles improve the dimensional stability of WPCs (Wang et al. 2004). Fu and Naguib (2006) studied composites reinforced with nanoclay particles and concluded that excessive amounts of nanoclay in composites resulted in weaker properties. Samariha et al. (2015) reported that the addition of $4 \%$ nanoclay into WPC made of recycled high-density polyethylene and bagasse flour reduces water absorption. Hemmasi et al. (2010) found that by adding only $2 \%$ nanoclay to the WPC made of pine wood flour and high-density polyethylene, water absorption and thickness swelling were reduced by $5 \%$ to $7 \%$.

The effects of cellulose nanofibers in many polymers as a nano-enhancer have been studied (Wegner and Jones 2006). Good mechanical properties, low density, and biodegradability are among the features that distinguish renewable cellulose nanoparticles from other nano-enhancers (Angles and Dufresne 2000). Cellulosic nanoparticles improve the water resistance of thermoplastic starch (Lu et al. 2005). Hydrogen bonding in WPCs stabilizes the starch matrix when it is exposed in a very humid environment (Svagan et al. 2009).

In this research, the effects of adding small amounts of nanocellulose fibers (NCF) or nanoclay (NC) particles in WPC made of thermoplastic starch and industrial sawdust were investigated. Tests of the physical and morphological properties including water absorption, thickness swelling, and degradation were performed. Dynamic mechanical thermal analysis (DMTA) tests were conducted to determine the glass transition temperature of WPCs and to study the thermal characteristics of WPC-containing nanoparticles. In addition for more morphological studies, scanning electron microscope (SEM) photography of fracture surface of WPCs were also conducted and observations and results are reported.

\section{EXPERIMENTAL}

\section{Composite and Sample Preparation}

Corn starch with $1.5 \mathrm{~g} / \mathrm{cm}^{3}$ density and a molar mass of $105 \mathrm{~g} / \mathrm{M}$ to $108 \mathrm{~g} / \mathrm{M}$ and glycerol with a density of $1.267 \mathrm{~g} / \mathrm{cm}^{3}$ and a molar mass of $92.09 \mathrm{~g} / \mathrm{M}$ as a plasticizer were used. These two ingredients were mixed to make the thermoplastic biodegradable polymer. Industrial sawdust, which was a mixture of beech, hornbeam, and walnut, was used as a filler. NCF with an average diameter of $35 \mathrm{~nm}$ was produced using the freeze dryer method. $\mathrm{NC}$ in the form of montmorillonite with a density of $0.5 \mathrm{~g} / \mathrm{cm}^{3}$ to $0.7 \mathrm{~g} / \mathrm{cm}^{3}$ and particle size of $1 \mathrm{~nm}$ to $2 \mathrm{~nm}$ was used. Maleic anhydride grafted polypropylene (MAPP) coupling agent with a melting flow index of $64 \mathrm{~g}$ per $10 \mathrm{~min}$ and a concentration of $2 \%$ was used to improve adhesion.

Sawdust and corn starch, which passed through a 60-mesh sieve, were placed in an oven at $60{ }^{\circ} \mathrm{C}$ for $24 \mathrm{~h}$. The corn starch was processed with $20 \mathrm{wt} \%$ glycerol in an internal mixer machine (Haake model HBI system 90, ThermoFisher, Waltham, MA, USA) for 3 min at $10 \mathrm{rpm}$ and $60{ }^{\circ} \mathrm{C}$. The resulting polymer was ground in an industrial grinder (Wiser, A-8992, Germany) in order to simulate the recycling condition. This thermoplastic polymer was mixed with specified amounts of $\mathrm{NCF}, \mathrm{NC}$, and sawdust at $100{ }^{\circ} \mathrm{C}$ in an internal mixer. To produce sheets of each composite sample type (code name A to E) a hot-pressing machine at $35 \mathrm{MPa}$ and $150{ }^{\circ} \mathrm{C}$ was utilized (Toyoseiki, Tokyo, Japan). Table 1 shows the composition (wt\%) of the materials in each sample type. 
Table 1. Composition of the Materials in each Nanocomposite Sample Type

\begin{tabular}{|c|c|c|c|c|c|}
\hline $\begin{array}{c}\text { Specimen } \\
\text { Code }\end{array}$ & $\begin{array}{c}\text { Polymer } \\
\text { wt\% }\end{array}$ & $\begin{array}{c}\text { Sawdust } \\
\text { wt\% }\end{array}$ & $\begin{array}{c}\text { Coupling agent } \\
\text { wt\% }\end{array}$ & $\begin{array}{c}\text { Nanoclay } \\
\text { wt\% }\end{array}$ & $\begin{array}{c}\text { Nanocellulose } \\
\text { wt } \%\end{array}$ \\
\hline A & 49.5 & 49.5 & 1 & 0 & 0 \\
\hline B & 48 & 48 & 1 & 3 & 0 \\
\hline C & 47 & 47 & 1 & 5 & 0 \\
\hline D & 48 & 48 & 1 & 0 & 3 \\
\hline E & 47 & 47 & 1 & 0 & 5 \\
\hline
\end{tabular}

\section{Methods}

Water absorption, thickness swelling, and degradation tests as well as DMTA tests were conducted according ASTM D7031-11 (2011) and ASTM D5271-02 (2002) using the designated WPCs. Each of the tests was repeated at least three times, and statistical analysis was conducted using SPSS software ver. 11.5 (IBM, Armonk, NY, USA).

\section{Thickness Swelling and Water Absorption}

Water absorption and thickness swelling tests were performed according to ASTM D7031-11 (2011). Samples were first dried in an oven and their initial weight and dimensions were determined. Then they were immersed in distilled water and their weights and thicknesses were measured after $72 \mathrm{~h}$ and $1000 \mathrm{~h}$.

\section{RESULTS AND DISCUSSION}

Figure 1a shows the thickness swelling of WPCs with different nanoparticle contents. Due to partial degradation and insufficient strength, thickness of specimens after $1000 \mathrm{~h}$ immersion in water was not measured accurately and results were only reported for $72 \mathrm{~h}$.
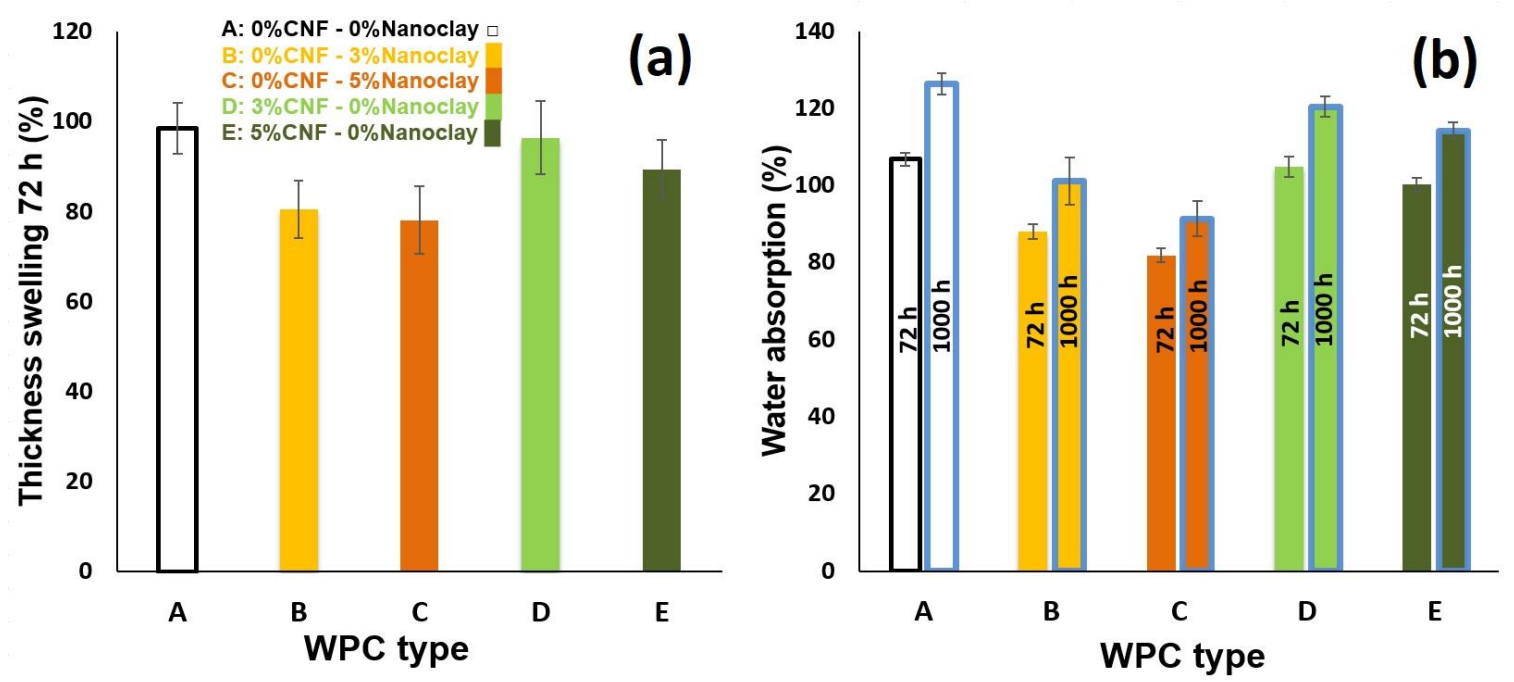

Fig. 1. Thickness swelling of WPCs after $72 \mathrm{~h}$ immersion in water (a), and water absorption of WPCs after $72 \mathrm{~h}$ and $1000 \mathrm{~h}(\mathrm{~b})$ 
Figure $1 \mathrm{~b}$ shows test results for water absorption of WPCs after $72 \mathrm{~h}$ and $1000 \mathrm{~h}$. The NC particle addition reduced water absorption and 5\% NC content was better than 3\% NC. However, adding CNF particles made no significant reduction in water absorption.

Table 2. Summary of Physical Test Results and Effect of Adding Nanoparticles

\begin{tabular}{|c|c|c|c|}
\hline $\begin{array}{c}\text { WPC type } \\
\text { /Comparison of properties: } \\
\boldsymbol{P}_{\mathbf{X} / \mathrm{A}}\end{array}$ & $\begin{array}{c}\text { Water } \\
\text { absorption } \\
(\%)\end{array}$ & $\begin{array}{c}\text { Thickness } \\
\text { swelling after } \mathbf{7 2} \\
\mathbf{h}(\%)\end{array}$ & $\begin{array}{c}\text { Thickness } \\
\text { swelling after } \\
\mathbf{1 0 0 0} \mathbf{~}(\%)\end{array}$ \\
\hline $\mathrm{A}:$ No Nano & 106.8 & 98.5 & 126.6 \\
\hline $\mathrm{B}: 3 \%$ NC & 88.0 & 80.6 & 101.2 \\
\hline $\mathrm{C}: 5 \%$ NC & 81.9 & 78.2 & 91.4 \\
\hline $\mathrm{D}: 3 \%$ CNF & 104.9 & 96.5 & 120.5 \\
\hline $\mathrm{E}: 5 \%$ CNF & 100.3 & 89.5 & 114.2 \\
\hline $\boldsymbol{P}_{\mathrm{B} / \mathrm{A}}$ & $\mathbf{- 1 8 . 8}$ & $\mathbf{- 1 7 . 9}$ & $\mathbf{- 2 5 . 4}$ \\
\hline $\boldsymbol{P}_{\mathrm{C} / \mathrm{A}}$ & $\mathbf{- 2 4 . 9}$ & $\mathbf{- 2 0 . 3}$ & $\mathbf{- 3 5 . 2}$ \\
\hline $\boldsymbol{P}_{\mathrm{D} / \mathrm{A}}$ & $\mathbf{- 1 . 9}$ & $\mathbf{- 2 . 0}$ & $\mathbf{- 6 . 1}$ \\
\hline $\boldsymbol{P}_{\mathrm{E} / \mathrm{A}}$ & $\mathbf{- 6 . 5}$ & $\mathbf{- 9 . 0}$ & $\mathbf{- 1 2 . 4}$ \\
\hline
\end{tabular}

Table 2 contains the water absorption and thickness swelling test results. The data is presented as a percentage change relative to the WPC type, as calculated by Eq. 1,

$$
P X / A=\left[P_{x}-P_{A}\right] \times 100 / P_{A}
$$

where $A$ reflects the effect of the added amount of nanoparticle on a specific physical characteristic. As shown in Table 2, adding 5\% NC resulted in better resistance to water absorption and thickness swelling than adding 3\% NC. By increasing the amount of nanoclay, water absorption and thickness swelling of WPCs were reduced. It seems that impermeability of clay nanoparticles prevented the penetration of water into the polymeric substrate.

Also, results showed that 5\% CNF reduced water absorption and thickness swelling more than adding $3 \% \mathrm{CNF}$. For a CNF reinforced composite, the study of water absorption is important due to hydrophilic nature of CNF. This phenomenon is described by extensive hydrogen bonding interactions between particles, starch matrix, and cellulose viscera. The interactions of hydrogen bonding in WPCs stabilizes the starch matrix when immersed in very humid environment. Also, high crystallinity of the cellulose can be a factor in reducing water absorption. Therefore, adding more nanoparticles resulted in better physical performance of the designated WPCs. Furthermore, the effect of adding NC was far better than adding $\mathrm{CNF}$ in terms of physical properties and performance.

\section{Dynamic Mechanical Thermal Analysis}

To determine thermal characteristics of WPCs, a DTMA device (Triton Technology Model Tritec DMTA 2000, Nottingham, UK) was used to evaluate the loss factor $(\tan \delta)$ and glass transition temperature $\left(T_{\mathrm{g}}\right)$. Tests were performed in temperatures ranging from $-100{ }^{\circ} \mathrm{C}$ to $150{ }^{\circ} \mathrm{C}$, with a heating rate of $4{ }^{\circ} \mathrm{C} / \mathrm{min}$ and load frequency of 1 $\mathrm{Hz}$. The effect of additional nanoparticles into WPCs on $\tan \delta$ curves acted as an indicator for DMTA behavior and extraction of glass transition temperature $\left(T_{\mathrm{g}}\right)$, as shown in Fig. 2. 

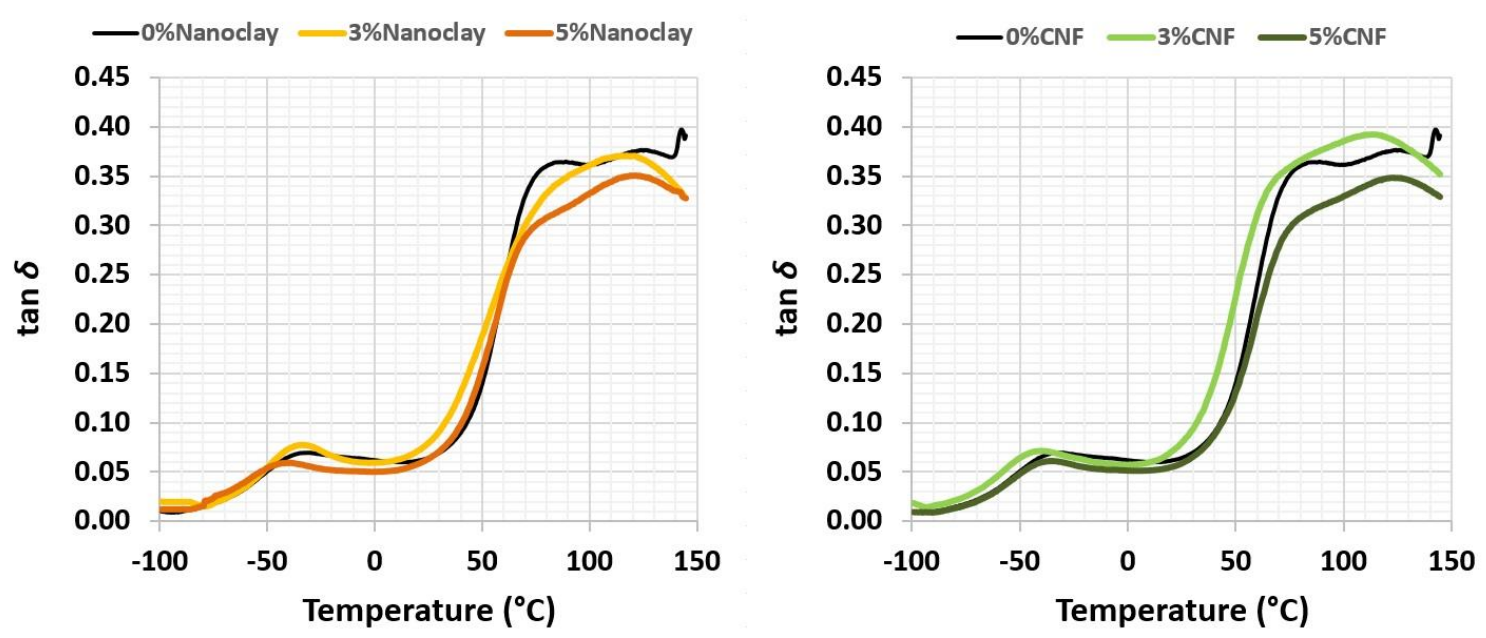

Fig. 2. Tan $\delta$ curves for WPCs with various amounts of nanoparticles

According to Fig. 2, the shape of $\tan \delta$ curves for all WPC types were almost identical. Two flat peaks were observed in all curves, which represented low and high glass transition temperatures, $T_{\mathrm{g} \alpha}$ and $T_{\mathrm{g} \beta}$, respectively. The $T_{\mathrm{g}}$ for WPCs with various amounts of nanoparticles are presented in Table 2 . The first (low) $T_{\mathrm{g}}\left(T_{\mathrm{g} \alpha}\right)$ is related to the glycerolrich phase and the second (high) $T_{\mathrm{g}}\left(T_{\mathrm{g} \beta}\right)$ is for the thermoplastic starch-rich phase. As shown in Table 3, with the addition and increase of nanoparticles into WPCs, there was no significant change in $T_{\mathrm{g} \alpha}$, due to the fixed and unchangeable nature of glycerol in the nanocomposites. In previous studies, $T_{\mathrm{g} \alpha}$ was also determined at $-50{ }^{\circ} \mathrm{C}$ (Korotkov et al. 2012; Hietala et al. 2013). However, increasing the amounts of nanoparticles into WPCs increased $T_{\mathrm{g} \beta}$ considerably, and $\mathrm{CNF}$ addition is the main reason for this improvement. Strong interactions between nanocellulose fibers and starch, limited the mobility of starch molecules and starch chains. This limitation made the WPCs more rigid and consequently, $T_{\mathrm{g} \beta}$ increased. Also NC can act as a nucleating agent and help the formation of crystalline structures in polymer matrix which leads to an increase in the temperature of thermal destruction of WPCs and improves its thermal properties. The broad width of the peaks indicated the heterogeneity of thermoplastic starch structures and nanoparticles into nanocomposites.

Table 3. Glass Transition Temperatures of Designated WPCs

\begin{tabular}{|c|c|c|}
\hline $\begin{array}{c}\text { Sample type/nanoparticle } \\
\text { content }\end{array}$ & $\begin{array}{c}\boldsymbol{T}_{\mathbf{g} \alpha}\left({ }^{\circ} \mathbf{C}\right) \\
\text { Low glass transition } \\
\text { temperature }\end{array}$ & $\begin{array}{c}\boldsymbol{T}_{\mathbf{g} \beta}\left({ }^{\circ} \mathbf{C}\right) \\
\text { High glass transition } \\
\text { temperature }\end{array}$ \\
\hline A: No nanoparticle & -37 & 89 \\
\hline B: 3\% Nanoclay & -38 & 112 \\
\hline C: 5\% Nanoclay & -36 & 119 \\
\hline D: 3\% Cellulose Nanofiber & -39 & 113 \\
\hline E: 5\% Cellulose Nanofiber & -38 & 123 \\
\hline
\end{tabular}




\section{Degradability Test}

To investigate the biodegradability of the designated WPCs, controlled active sludge environment was used according to ASTM D5271-02 (2011). Each type of WPC was prepared and dried in an oven at $60{ }^{\circ} \mathrm{C}$ for $24 \mathrm{~h}$. The dried specimens were placed in an active sludge bath. Specimens remained in the medium for two months, and each week, they were removed and reweighed. Differences between weights during these time intervals and initial weights were considered as a measure of biodegradability.

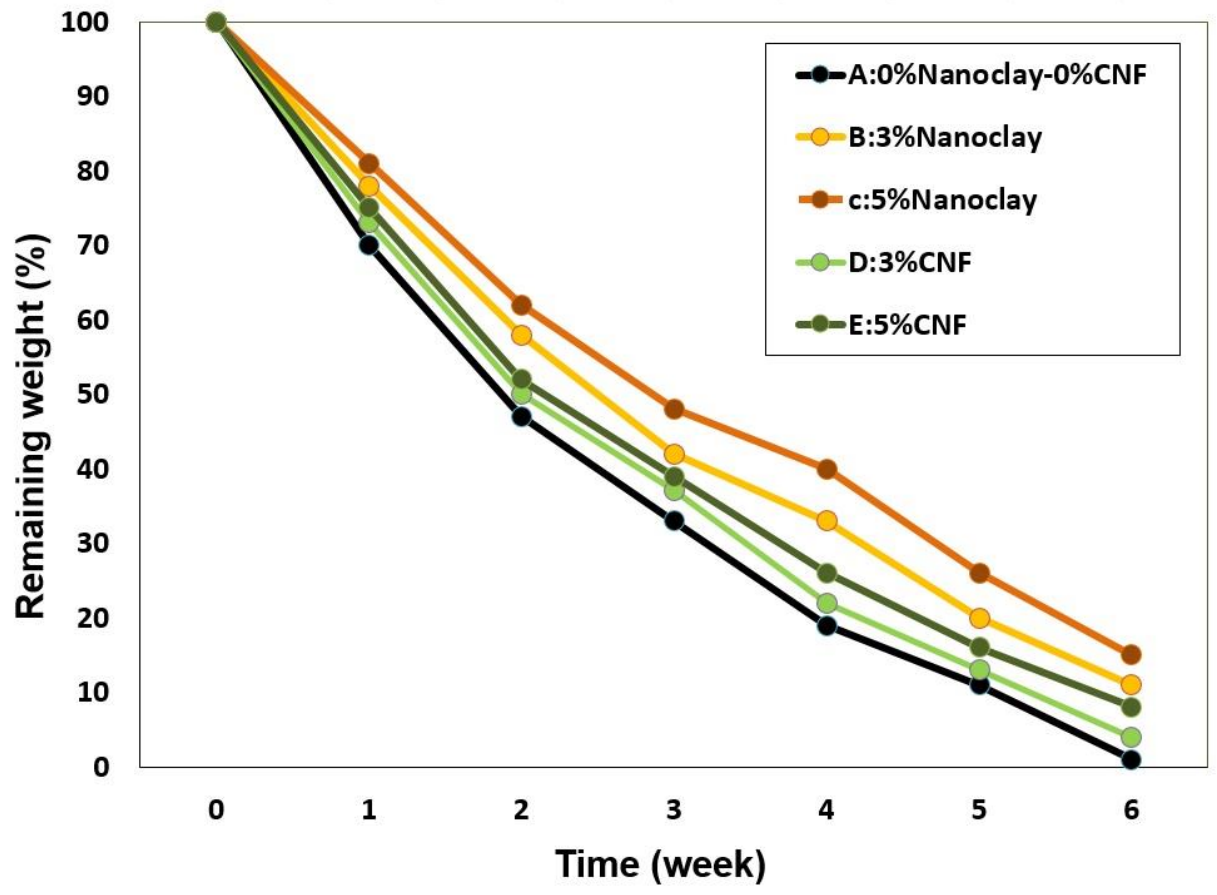

Fig. 3. Remaining weights of various WPCs under biodegradability test

Figure 3 shows the calculated remaining weights of each WPC. The kinetics of biodegradation were attributed to high concentrations of starch within WPCs and their consumption by microorganisms. Because the thermoplastic starch content of all WPC types was identical, the time for degradation of them was close to each other. Although WPC type "A" with no nanoparticles added degraded faster than any other WPC type, all WPC types degraded with less than $20 \%$ of their weight remaining after 6 weeks. The CNF caused the particles to aggregate and delayed the release of water and oxygen molecules that passed through them; thus it delayed the rapid growth of microorganisms and their attacks, which increased the amount of CNF content into the WPC and decreased degradability of the composite. By adding NC particles into the WPC structure, the rate of degradability was reduced.

\section{Scanning Electron Microscope Observations}

For more observations in this study, microstructure of WPCs was investigated on fracture surfaces using electron microscopy (SEM). Appropriate fracture surfaces were created at liquid nitrogen temperature. By observing and examining the images obtained from the electron microscope, the distribution and compatibility between the fillers (industrial sawdust and added nanoparticles) and matrix (thermoplastic starch) can be investigated. 


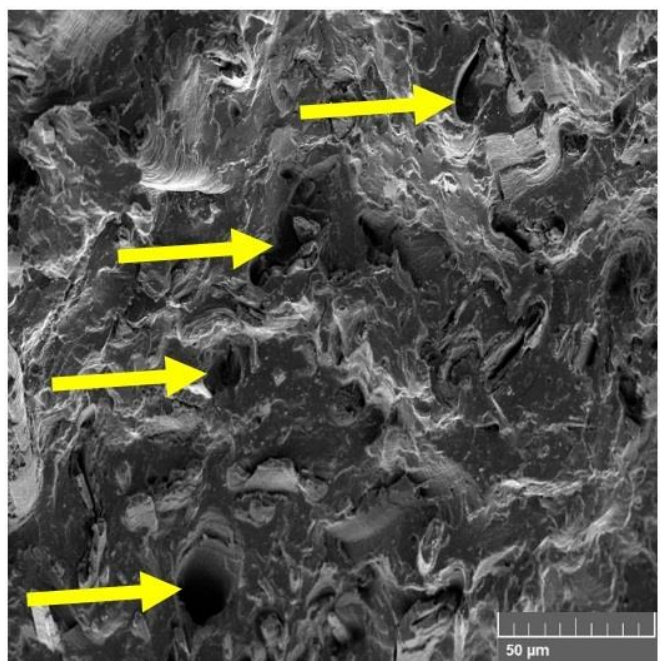

Fig. 4. Fracture surface of WPC type "A" with no nanoparticle content; arrows: separation of fibers from the matrix due to weak connections

In Fig. 4, the SEM fracture surface of WPC without any nanoparticle addition (type A) is presented. Yellow arrows, which show the vacant spaces (cavities) imply a poor binding surfaces between the fibers and the matrix in absence of any nanoparticle addition. This means that by applying tension or pressure the fibers are separated from the matrix surface due to weak connections between them.
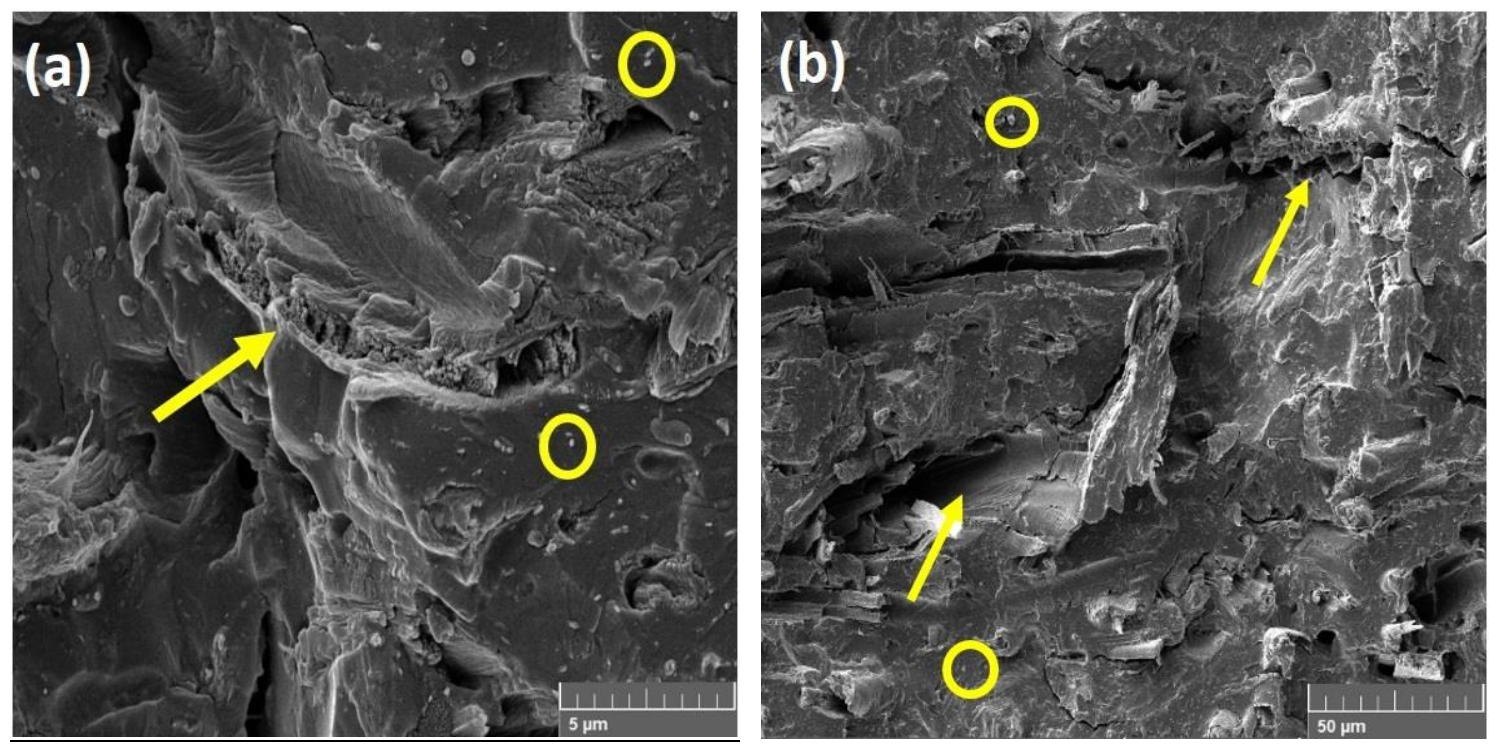

Fig. 5. Fracture surface of (a) WPC type "B" with $3 \%$ NC and (b) WPC type "C" with $5 \%$ NC; circles: NC particles dispersion into the matrix; arrows: fracture of fibers inside the matrix due to improved adhesion

In Fig. 5, yellow arrows show condition of contact (implying adhesion) or cavities, and yellow circles show NC particles dispersion into the composite. Figure 5(a) shows that the adhesion between fibers and polymeric phase was improved by adding $3 \%$ nanoclay; in this figure a decrease in cavities implies this improvement. Figure 5(b) is a SEM image of WPC with 5\% NC; this image shows that the adhesion between the matrix and fibers was weakened in comparison to the previous image (Fig. 5 (a)) and in some areas, cavities 
and cracks nucleated at fiber separation spots. According to tensile and flexural test results, the increase in $\mathrm{NC}$ content from $3 \%$ to $5 \%$ reduced these mechanical properties. To interpret this behavior, a legitimate reason can be the adsorption of coupling agent by NC particles (Shu-Kai 2010). By increasing nanoclay amounts, coupling agent absorption increases, so the coupling agent does not establish a suitable connection between the matrix and lignocellulosic materials, which reduces the tensile and flexural strength. In Fig. 6, yellow arrows show condition of bonds, and yellow circles show some CNF particles dispersion into the composite. Figures 6(a) and (b) show that by adding 3\% and 5\% cellulose nanofibers, the strengths of bonds and joint surfaces were higher. Transfer of stresses between fibers and matrix was more effective, leading to better mechanical properties.
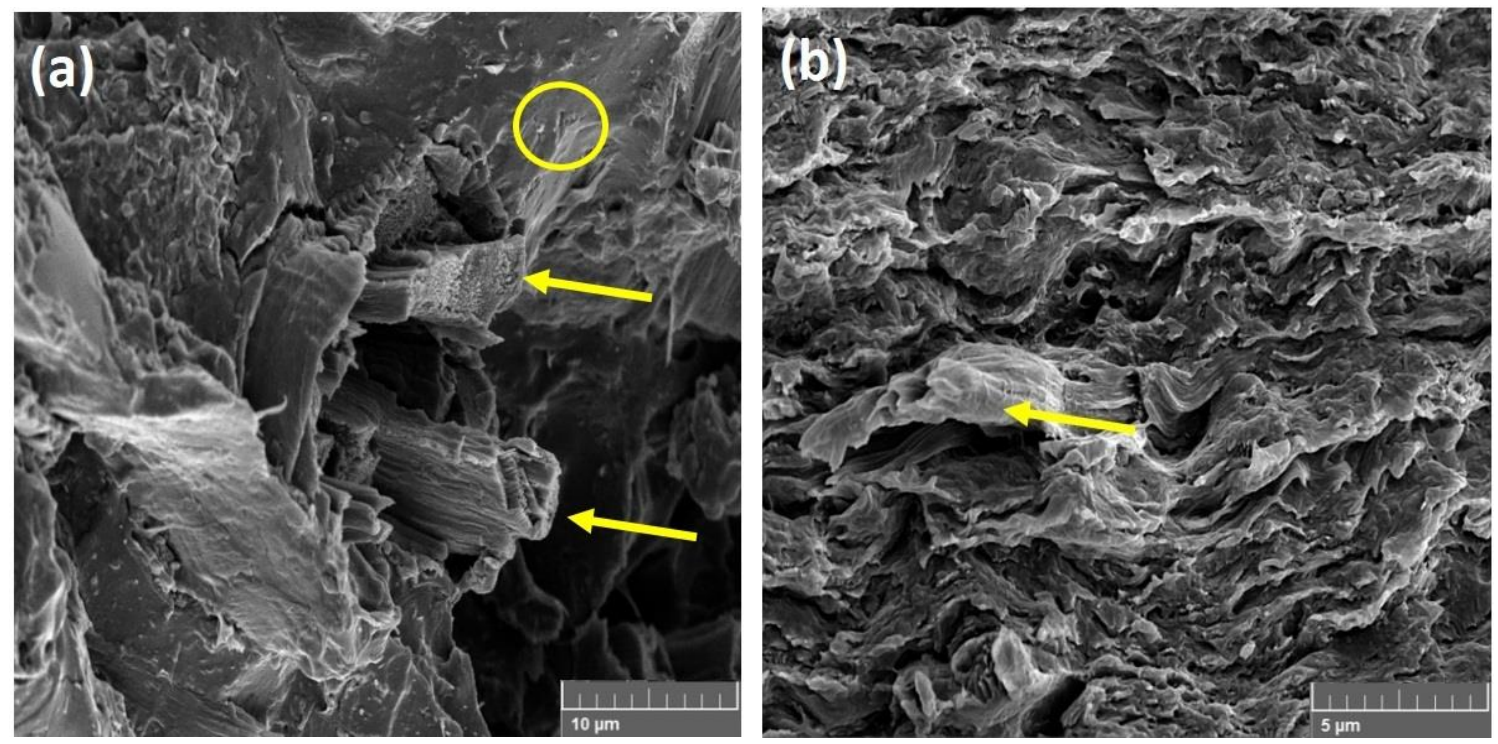

Fig. 6. Fracture surface of (a) WPC type "D" with $3 \%$ CNF and (b) WPC type "E" with $5 \%$ CNF; circles: CNF particles dispersion into the matrix; arrows: condition of bonds

According to the images taken and presented in this study, it was observed that WPCs without nanoparticle addition had the lowest amount of adhesion between fillers (industrial sawdust) and matrix (thermoplastic starch). In the WPCs, the fracture surfaces showed weak adhesion and relatively large heterogeneity. In the corresponding images, the presence of cavities and holes reflected this issue.

\section{CONCLUSIONS}

1. The addition of cellulose nanofibers and nanoclay particles into the starch-sawdust biocomposite structure improved physical and morphological characteristics.

2. Adding 5\% nanoparticles resulted in better properties than adding 3\% nanoparticles, thus with increased nanoparticles the physical properties improved.

3. In terms of water resistance, nanoclay led to better dimensional stability.

4. Cellulose nanofibers addition led in higher glass transition temperatures $\left(T_{\mathrm{g} \beta}\right)$. 
5. Addition of nanoparticles slightly decreased degradation process speed, but this reduction did not affect the overall biodegradability of WPCs.

\section{REFERENCES CITED}

Angles, M. N., and Dufresne, A. (2000). "Plasticized starch/tunicin whiskers nanocomposites. 1. Structural analysis," Macromolecules 33(22), 8344-8353. DOI: $10.1021 / \mathrm{ma0008701}$

ASTM D7031-11 (2011). "Standard guide for evaluating mechanical and physical properties of wood-plastic composite products," ASTM International, West Conshohocken, PA. DOI: 10.1520/D7031-11

ASTM D5271-02 (2002). "Standard test method for determining the aerobic biodegradation of plastic materials in an activated-sludge-wastewater-treatment system (withdrawn 2011)," ASTM International, West Conshohocken, PA. DOI: 10.1520/D5271-02

Beigloo, J. G., Eslam, H. K., Hemmasi, A. H., Bazyar, B., and Ghasemi, I. (2017). "Effect of nanographene on physical, mechanical, and thermal properties and morphology of nanocomposite made of recycled high density polyethylene and wood flour," BioResources 12(1), 1382-1394. DOI: 10.15376/biores.12.1.1382-1394

Cunha, A. G., and Gandini, A. (2010). "Turning polysaccharides into hydrophobic materials: A critical review. Part 1 Cellulose," Cellulose 17(5), 875-889. DOI: 10.1007/s10570-010-9434-6

Dufresne, A., and Vignon, M. R. (1998). "Improvement of starch film performances using cellulose microfibrils," Macromolecules 31(8), 2693-2696. DOI: 10.1021/ma971532b

Eslam, H. K., Saieh, S. E., and Rajabi, M. (2011). "Effect of steaming treatment on the physical and mechanical properties of WPC made of cotton flour and polypropylene," Australian Journal of Basic and Applied Science 5(6), 1143-1150.

Eslam, H. K., and Samariha, A. (2015). "Effect of steamed and non-steamed Populus deltoides fiber on the physical, mechanical, and morphological characteristics of composites made from virgin polypropylene," BioResources 10(4), 8439-8449. DOI: 10.15376/biores.10.4.8439-8449

Fu, J., and Naguib, H. E. (2006). "Effect of nanoclay on the mechanical properties of PMMA/clay nanocomposite foams," Journal of Cellular Plastics 42(4), 325-342. DOI: $10.1177 / 0021955 X 06063517$

Hemmasi, A. H., Khademi-Eslam, H., Talaiepoor, M., Kord, B., and Ghasemi, I. (2010). "Effect of nanoclay on the mechanical and morphological properties of wood polymer nanocomposite," Journal of Reinforced Plastics and Composites 29(7), 964971. DOI: $10.1177 / 0731684408101790$

Hietala, M., Mathew, A. P., and Oksman, K. (2013). "Bionanocomposites of thermoplastic starch and cellulose nanofibers manufactured using twin-screw extrusion," European Polymer Journal 49(4), 950-956. DOI: 10.1016/j.eurpolymj.2012.10.016

Jiménez Marco, A., Fabra Rovira, M. J., Talens Oliag, P., and Chiralt, A. (2012). "Edible and biodegradable starch films: A review," Food and Bioprocess Technology 5(6), 2058-2076. DOI: 10.1007/s11947-012-0835-4

Keller, A. (2003). "Compounding and mechanical properties of biodegradable hemp fiber 
composites," Composites Science and Technology 63(9), 1307-1316. DOI:

10.1016/S0266-3538(03)00102-7

Korotkov, A. N., Voskoboinikov, I. V., Konstantinova, S. A., Gal'braikh, L. S., and Mikhailov, A. I. (2012). "Some observations on obtaining cellulose nanocrystals," Fibre Chemistry 43(5), 339-343. DOI: 10.1007/s10692-012-9359-y

Lu, Y., Weng, L., and Cao, X. (2005). "Biocomposites of plasticized starch reinforced with cellulose crystallites from cottonseed linter," Macromolecular Bioscience 5(11), 1101-1107. DOI: 10.1002/mabi.200500094

Samariha, A., Hemmasi, A. H., Ghasemi, I., Bazyar, B., and Nemati, M. (2015). "Effect of nanoclay contents on properties of bagasse flour/reprocessed high-density polyethylene/nanoclay composites," Maderas. Ciencia y Tecnología 17(3), 637-646. DOI: $10.4067 / \mathrm{S} 0718-221 \mathrm{X} 2015005000056$

Shu-Kai, Y. (2010). "Nanoclay-reinforced, polypropylene-based wood-plastic composites," Polymer Engineering and Science 50(10), 20130-2020.

Svagan, A. J., Hedenqvist, M. S., and Berglund, L. (2009). "Reduced water vapor sorption in cellulose nanocomposites with starch matrix," Composites Science and Technology 69(3-4), 500-506. DOI: 10.1016/j.compscitech.2008.11.016

Teixeira, E. D. M., Curvelo, A. A., Corrêa, A. C., Marconcini, J. M., Glenn, G. M., and Mattoso, L. H. (2012). "Properties of thermoplastic starch from cassava bagasse and cassava starch and their blends with poly (lactic acid)," Industrial Crops and Products 37(1), 61-68. DOI: 10.1016/j.indcrop.2011.11.036

Wang, H., Zeng, C., Elkovitch, M., Lee, L. J., and Koelling, K. W. (2004). "Processing and properties of polymeric nano-composites," Polymer Engineering and Science 41(11), 2036-2046. DOI: 10.1002/pen.10899

Wegner, T. H., and Jones, P. E. (2006). "Advancing cellulose-based nanotechnology," Cellulose 13(2), 115-118. DOI: 10.1007/s10570-006-9056-1

Article submitted: January 9, 2019; Peer review completed: April 7, 2019; Revisions accepted: April 29, 2019; Published: May 17, 2019.

DOI: 10.15376/biores.14.3.5278-5287. 